doi:10.12662/2359-618xregea.v10i1.p214-225.2021

ARTIGOS

\section{CONSISTÊNCIA E CONVERGÊNCIA CONTÁBIL: RELEVANTES PARA TRANSPARÊNCIA NA ADMINISTRAÇÃO PÚBLICA?}

\author{
CONSISTENCY AND ACCOUNTING \\ CONVERGENCE: RELEVANT TO TRANSPARENCY \\ IN PUBLIC ADMINISTRATION?
}

\section{RESUMO}

O objetivo desta pesquisa foi identificar a relevância da consistência e da convergência contábil no nível de transparência dos municípios do Estado de Pernambuco. A amostra contou com os 184 municípios do Estado de Pernambuco. $\mathrm{O}$ ano analisado foi o de 2015. A análise revelou que é de $42 \%$, em média, a transparência dos municípios pernambucanos em relação à gestão pública. Houve relação positiva e estatisticamente significativa para duas variáveis, o PIB e o tamanho da população, o que indica que, quanto maior for o PIB e a população, mais transparentes são na gestão pública serão os munícipios. Por fim, na ANACOR, os dois índices são independentes (não estão relacionados). Assim, podemos afirmar que não se regista uma relação entre o índice de transparência municipal e o índice de consistência e convergência contábil.

Palavras-chave: Consistência Contábil. Convergência Contábil. Transparencial.

\begin{abstract}
The objective of this research was to identify the relevance of accounting consistency and convergence in the level of transparency of the municipalities of the State of Pernambuco. The sample included the 184 municipalities of the state of Pernambuco. The year analyzed was 2015 . The analysis revealed that it is $42 \%$, on average, the transparency of Pernambuco municipalities in relation to public management. There was a positive and statistically significant relationship for two variables, GDP and population size, which indicates that the higher the GDP and population, the more transparent in public management the municipalities are. Finally, in ANACOR the two indexes are independent (not related). Thus, we can affirm that there is no relationship between the municipal
\end{abstract}


transparency index and the accounting consistency index and convergence index.

Keywords: Accounting Consistency. Accounting Convergence. Transparency.

\section{INTRODUÇÃO}

No Brasil, em 2008, diversas normas vieram para modernizar a contabilidade aplicada ao setor público, outras novas normas também ocorreram até o ano de 2013. Tamanhas foram essas mudanças, que a academia e a sociedade batizaram esse processo de "nova" contabilidade aplicada ao setor público. De maneira intrínseca nessas normas estão a consistência e a convergência contábil.

Tanto na literatura internacional, Christiaens (2004), Dutta e Reichelstein (2005) e Zeff (2007), quanto na nacional, Sousa et al. (2013) afirmam que, em relação à estrutura de gestão e à contabilidade do setor público, vários países têm experimentado mudanças profundas. Estudo realizado por Ernest \& Young (2010) reforça que uma estrutura contábil robusta e um conjunto uniforme de normas para o setor público são entendidos como necessários para trazer estabilidade ao sistema econômico global e aumentar a accountability e eficiência dos governos.

No que diz respeito à convergência contábil e transparência da administração pública, Vicente, Morais e Platt Neto (2012) afirmam que a Resolução CFC n. ${ }^{\circ} 1.103 / 07$ criou o Comitê Gestor da Convergência no Brasil com o objetivo de contribuir com o desenvolvimento sustentável do Brasil por meio de uma reforma contábil e de auditoria que promova maior transparência das informações e aprimoramento das práticas profissionais, observando a convergência aos padrões internacionais (CONSELHO FEDERAL DE CONTABILIDADE, 2007).

Corroborando esse entendimento, Soares e Scarpim (2010) afirmam que, com a edição das NBCASP, torna-se possível que a contabilidade evidencie todos os componentes patrimoniais e, como consequência, considere os fatos anteriores, atuais ou futuros, que não tenham relação direta com a execução do orçamento anual. Após a disseminação e harmonização desses conceitos em nível nacional, será possível a tão esperada e necessária convergência às normas internacionais.

Essa reforma também colaborou para o fortalecimento da transparência na administração pública, reforçando o disposto já contido desde 2001 na Lei de Responsabilidade Fiscal/ LRF. De acordo com Vignoli (2002) e Sacramento (2005) ao contemplar uma série de relatórios e demonstrativos que permitem comparar o que foi orçado com o que foi executado e que tais instrumentos serão objetos de ampla divulgação, a LRF consagra o real entendimento de transparência na gestão pública.

Diante desse contexto, a partir de 2015, o Tribunal de Contas do Estado de Pernambuco (TCE/PE) elaborou dois índices na tentativa de mensurar o grau de consistência e convergência contábil e o de transparência da administração pública, isso no que tange a todos os municípios do referido estado.

Assim, seguindo-se as evidências apresentadas, torna-se oportuno analisar a relação entre a consistência e a convergência contábil e o nível de transparência da administração pública. Dessa forma, emerge a seguinte questão norteadora desta pesquisa: A Consistência e a convergência contábil são relevantes para a transparência na administração pública nos municípios do Estado de Pernambuco? Este trabalho tem como objetivo identificar a relevância da consistência e da convergência contábil no nível de transparência dos municípios do Estado de Pernambuco.

Amaral e Lima (2013) afirmam que o Brasil vive um momento histórico na contabilidade pública, voltado para o processo de convergência aos padrões contábeis internacionais. De acordo com Veja et al. (2015), somente a partir de 2013, a aplicação da contabilidade aplicada ao setor público tornou-se obrigatória para os municípios de todo o país, o que motivou o TCE/PE a elaborar um ranking sobre a consistência e convergência contábil dos municípios em relação à contabilidade pública 
vigente a partir de 2015. O TCE/PE também elaborou e divulga um ranking sobre a transparência governamental dos 184 municípios pernambucanos desde 2014. Diante dessas circunstâncias, a seguinte hipótese foi formulada:

$\mathrm{H}_{1}$ : Existe relação positiva entre a transparência governamental e a consistência e convergência contábeis nos municípios do estado de Pernambuco.

Para o alcance desse objetivo, foi realizada uma pesquisa descritiva, documental e quantitativa; o ano analisado foi o de 2015, os dados foram extraídos das seguintes fontes: do Tribunal de Contas do Estado de Pernambuco (TCE$\mathrm{PE}$ ), os índices de consistência e convergência contábil e o índice de transparência da gestão pública, e do Instituto Brasileiro de Geografia e Estatística (IBGE), o Índice de Desenvolvimento Humano/IDH, o Produto Interno Bruto/PIB e o tamanho da população de cada município.

Este estudo busca contribuir para a ampliação das investigações que tentam explicar a relevância da nova contabilidade pública na administração pública. Desse modo, esta pesquisa justifica-se por abordar tema atual, relevante e de interesse da academia e da sociedade.

\section{REVISÃO DE LITERATURA}

\subsection{CONVERGÊNCIA E CONSISTÊNCIA CONTÁBIL E TRANSPARÊNCIA NA ADMINISTRAÇÃO PÚBLICA}

Segundo Gama, Duque e Almeida (2014), no Brasil, as International Public Sector Accounting Standards (IPSAS), conhecidas por Normas Internacionais de Contabilidade para o Setor Público (NICSP), são padrões internacionais de alta qualidade criadas para melhorar a elaboração de demonstrações contábeis pelo setor.

Feijó e Bugarim (2008) demonstram que o Conselho Federal de Contabilidade (CFC), órgão responsável pela orientação, normatização e fiscalização da profissão contábil no Brasil, iniciou a chamada convergência no setor público ao instituir, por meio da Portaria CFC n. ${ }^{\circ}$ 37/2004, o Grupo de Estudos voltado para a área pública brasileira. Ainda segundo os autores, as ações do CFC de alinhamento à primeira diretriz materializaram-se com a publicação, em 21 de novembro de 2008, das dez primeiras Normas Brasileiras de Contabilidade Aplicadas ao Setor Público (NBCASP).

Macêdo et al. (2010) esclarecem que esse conjunto de documentos, além de anunciar uma série de mudanças conceituais, visam promover maior aproximação entre a ciência contábil e a contabilidade pública, com vistas à convergência das NBCASP às IPSAS.

No que se refere à consistência, Wustemann e Wustemann (2010) categorizam duas noções de consistência: 1) de um lado, a consistência interna das normas contábeis; e 2) do outro lado, a consistência da aplicação daquelas normas.

Ainda sobre a consistência, Paulo, Carvalho e Girão (2014) afirmam que, se não houvesse à consistência na aplicação das normas, o enforcement dos reguladores ficaria prejudicado, assim como a comparabilidade e a objetividade das informações.

No que tange à transparência da administração pública, Silva (2009) afirma que a disponibilização de informações transparentes, tempestivas e relevantes acerca da gestão pública e da alocação dos recursos públicos por parte dos governantes constitui um ato de responsabilidade na prestação de contas, o que a literatura denomina de accountability. Ademais, o acesso à informação é um direito fundamental estabelecido pelo art. $5^{\circ}$, inciso XXXIII da Constituição Federal de 1988 (BRASIL, 1988).

Platt Neto et al. (2007) afirmam que mais do que garantir o atendimento das normas legais, as iniciativas de transparência na administração pública constituem uma política de gestão responsável que favorece o exercício da cidadania pela população. Corroborando esse entendimento sobre transparência na administração pública, Nuno et al. (2016) e Barros et al. (2017) definem que a transparência representa um instrumento que possibilita uma melhor gestão dos recursos públicos, estabelecen- 
do regras claras e precisas a todos os gestores e em todas as esferas.

Porém, os resultados de Kreutz e Lock (2020) apontam para outra direção, as evidências empíricas apontam para a inexistência da disponibilidade de informações sobre o processo de gestão dos projetos de mobilidade urbana do município. Corroborando, Tavares e Romão (2021) afirmam que, apesar do esforço que o Brasil vem empreendendo para aumentar a transparência no processo de decisões das políticas públicas, possui desafios estruturais que demandam muito mais esforços.

\section{2 ÍNDICES DE CONSISTÊNCIA E CONVERGÊNCIA CONTÁBIL E ÍNDICE DE TRANSPARÊNCIA NO ESTADO DE PERNAMBUCO}

Em relação à consistência e convergência contábil, de acordo com o TCE/PE (PERNAMBUCO, 2016), foi realizado um diagnóstico para verificar o cumprimento, por parte dos municípios pernambucanos, das regras de contabilidade pública, no tocante ao grau de convergência e consistência exigidos, conforme preconiza o art. 12, parágrafo único da Portaria - STN 604/2013 c/c o art. 51 da LRF. O objetivo do Índice de Consistência e Convergência/ICCPE, em resumo, é o de aferir o nível mínimo de informações contábeis publicadas pelos Entes jurisdicionados do TCE/PE, em suas prestações de contas, quanto ao nível de padronização e consistência contábil, que permita garantir fidelidade aos fenômenos orçamentários, financeiros e patrimoniais das transações escrituradas pelos segmentos de contabilidade desses Entes.

Os critérios de avaliação do ICC/PE foram organizados em dois grupos:

No grupo da Convergência: 1) estrutura e forma de apresentação do balanço orçamentário; 2) estrutura e forma de apresentação do balanço financeiro; 3 ) estrutura e forma de apresentação do balanço patrimonial; 4) estrutura e forma de apresentação da demonstração das variações patrimoniais; 5) estrutura e forma de apresentação da demonstração de fluxo de cai- xa; e 6) estrutura e forma das notas explicativas a aspectos gerais.

No grupo da consistência: 1) consistência entre as informações prestadas na PC eletrônica x SICONFI; e 2) consistências dos saldos dos balanços.

No que diz respeito à transparência da administração pública, segundo o TCE/PE (PERNAMBUCO, 2016), o objetivo da criação do índice foi realizar o diagnóstico dos portais da transparência das prefeituras municipais do estado de Pernambuco, para o exercício 2015, mediante o estabelecimento de um Índice de Transparência, o ITM/PE - Índice de Transparência dos Municípios de Pernambuco, com o intuito de estimular a melhoria da transparência pública e, consequentemente, facilitar o controle social. A avaliação dos portais da transparência das prefeituras de Pernambuco tomou por base as exigências contidas na Lei Complementar $n^{\circ} 101 / 2000$ (BRASIL, 2000) (Lei de Responsabilidade Fiscal), na Lei Complementar no 131/2009, que determina a disponibilização, em tempo real, de informações sobre a execução orçamentária e financeira, no Decreto $\mathrm{n}^{\circ} 7.185 / 2010$, que regulamenta a LC $n^{\circ} 131 / 2009$, e na Lei $n^{\circ} 12.527 / 2011$ (LAI), que regulamenta o acesso à informação previsto no inciso XXXIII do art. $5^{\circ}$ da Constituição Federal de 1988.

Os critérios de avaliação do ITM/PE também foram organizados em dois grupos:

Grupo de conteúdo: 1) Transparência da gestão fiscal; e 2) Lei de acesso à informação.

Grupo de requisitos tecnológicos: 1) Do sítio do portal da transparência; 2) Da sessão receita; 3) Da sessão despesa; 4) Da sessão licitações; 5) Da sessão contratos.

\section{METODOLOGIA}

\subsection{DADOS E SELEÇÃO DA AMOSTRA}

A amostra do presente estudo é composta pelos 184 municípios do Estado de Pernambuco. Para fazer parte da amostra, foi necessário que as 
informações relativas ao índice de consistência e convergência contábil e ao índice de transparência da administração pública, relativas ao ano de 2015, estivessem disponíveis no portal eletrônico do TCE/PE. Não foram considerados nas análises anos mais recentes, devido a mudanças em alguns critérios dos índices, o que tornaria equivocada qualquer tipo de análise.

\subsection{VARIÁVEIS UTILIZADAS E MODELOS ECONOMÉTRICOS}

\subsubsection{Variável dependente}

Para mensuração da transparência da administração pública, este trabalho considerou o índice de transparência dos municípios do Estado de Pernambuco referente ao ano de 2015, apresentado pelo TCE/PE, em 2016, em seu sítio eletrônico. Dessa forma, a variável dependente tem natureza numérica. Cada município recebeu uma nota entre 0 e 1.000 , a depender de divulgação de itens sobre conteúdo e requisitos tecnológicos.

\subsubsection{Variáveis independentes}

No que se refere à mensuração da consistência e convergência contábil, este trabalho considerou o índice de consistência e convergência contábil dos municípios do Estado de Pernambuco referente ao ano de 2015, divulgado pelo TCE/PE, em 2016, em seu sítio eletrônico. Dessa forma, as variáveis independentes são de natureza quantitativa, tendo cada município recebido notas de $0 \%$ a $100 \%$ para essas duas variáveis.

\subsubsection{Variáveis de controle e de desempenho}

A variável de controle escolhida foi o tamanho da população do município, dado esse coletado no site do IBGE. Para fins de teste do modelo, o tamanho da população foi transformado em logaritmo natural, para atenuar diferenças entre os tamanhos das populações. Como variáveis de desempenho, foram esco- lhidas duas variáveis já consagradas em estudos econômicos, o IDH e o PIB, variáveis estas também coletadas diretamente no site do IBGE.

\subsubsection{Modelo econométrico}

Diante das variáveis dependente, independentes, de controle e de desempenho apresentadas, foi elaborado modelo na tentativa de responder à questão norteadora dessa pesquisa:

$$
\begin{aligned}
& \mathrm{ITM}_{\mathrm{i}},=\alpha+\beta 1 \mathrm{CC}_{\mathrm{i}},+\beta 2 \mathrm{CCG}_{\mathrm{i}},+\beta 3 \mathrm{TAM}_{\mathrm{i}}, \\
& +\beta 4 \mathrm{IDH}_{\mathrm{i}},+\beta 5 \mathrm{PIB}_{\mathrm{i}}, \varepsilon \\
& \text { Em que, } \mathrm{ITM}_{\mathrm{i}} \text {, é o índice de transparên- } \\
& \text { cia municipal; } \\
& \alpha \text { é o intercepto da reta; } \\
& \beta \text { são os coeficientes angulares; }
\end{aligned}
$$

Ademais, $\mathrm{CC}_{\mathrm{i}}$, (Consistência Contábil), $\mathrm{CCG}_{\mathrm{i}}$, (Convergência Contábil) são as variáveis independentes.

$\mathrm{TAM}_{\mathrm{i}}$, (Tamanho da população do município) é a variável de controle.

$\mathrm{IDH}_{\mathrm{i}}$, (Índice de desenvolvimento humano do município) e PIB, (Produto Interno Bruto do município) são as variáveis de desempenho. $\varepsilon$ é o termo de erro.

\subsection{TRATAMENTO ESTATÍSTICO}

Os dados foram analisados por meio de estatística descritiva, com indicação de máximos e mínimos, média e desvio padrão, a fim de comparar os resultados obtidos para os índices e as demais variáveis. Após essa análise, foi ajustado um modelo de regressão linear múltipla; porém, antes de testar o modelo, foi realizado o teste VIF para verificar a existência de multicolinearidade entre as variáveis do modelo. Para finalizar, foi realizada Análise de Correspondência (Anacor); para operacionalização dessa análise, os índices foram categorizados de acordo com o esperado pelo TCE/PE.

\section{ANÁLISE DOS RESULTADOS}

A análise dos dados obtidos com a coleta 
dos dados foi dividida em duas fases: descritiva e econométrica. $\mathrm{Na}$ análise descritiva, o foco das análises foi as médias obtidas pelos municípios, assim como os valores máximos que algum município conseguiu obter. Na parte econométrica, antes de ajustar o modelo, foi realizado teste VIF e de tolerância, com o intuito de verificar se alguma variável independente tem relação uma com as outras.

\subsection{ANÁLISE DESCRITIVA}

A primeira análise foi referente aos índices que compõem o modelo econométrico, o ITM, ICC e ICG. Na tabela 1, são evidenciados soma, máximos e mínimos. Mediana, moda, média e desvio padrão, além da divisão da amostra por percentil. critérios de transparência estabelecidos pelo TCE/PE.

A média de transparência dos municípios foi de pouco mais de $42 \%$. Esses resultados estão alinhados com as evidências encontradas na pesquisa de Cruz et al. (2012) que concluíram que os maiores municípios brasileiros apresentaram um nível de transparência de informações da gestão pública municipal incompatível com seu desenvolvimento socioeconômico.

No que diz respeito à consistência contábil, o município que mais foi consistente conseguiu $95 \%$ dos $100 \%$ possíveis, e o de menor, apenas $9 \%$. Cabe a observação de que houve uma alta média de consistência contábil dos municípios que foi de mais de $75 \%$. Finalmente, em relação à convergência contábil, o máximo que algum município conseguiu obter foi

Tabela 1 - Estatística descritiva dos índices ITM, ICC e ICG

\begin{tabular}{lcccc}
\hline \hline & & ITM & Consistência contábil & Convergência contábil \\
\hline \multicolumn{1}{c}{$\mathrm{N}$} & Válido & 184 & 184 & 184 \\
& Ausente & 0 & 0 & 0 \\
Média & & 422.9606 & 75.6739 & 68.4671 \\
Mediana & & 470.5000 & 80.0000 & 69.0000 \\
Modo & .00 & 86.00 & 66.00 \\
Desvio Padrão & & 177.88479 & 14.68140 & 8.87655 \\
Variância & & 21642.999 & 215.543 & 78.793 \\
Mínimo & & 900 & 9.00 & 19.95 \\
Máximo & & 77824.75 & 13924.00 & 88.50 \\
Soma & & 314.8750 & 69.0000 & 12597.95 \\
& 25 & 470.5000 & 80.0000 & 66.0000 \\
Percentis & 50 & 556.5000 & 86.0000 & 69.0000 \\
& 75 & & & 72.0000 \\
\hline \hline
\end{tabular}

Fonte: dados da pesquisa (2017).

Diante dos resultados, pode-se inferir que, no que se refere à transparência, de onde cada munícipio poderia auferir 1.000 pontos, o máximo que algum município conseguiu foi 800.50 pontos, ou pouco mais de $80 \%$ do que era possível. Porém, cabe ressaltar uma forte dominância da pontuação zero, levando a afirmar que mais de um município não está cumprindo absolutamente nada no que tange aos de pouco mais de $88 \%$ dos $100 \%$ possíveis, e o menor quase $20 \%$.

A convergência contábil também conseguiu uma alta média, mais de $68 \%$, o município mais convergente conseguiu um índice de mais de $88 \%$. Todos os índices apresentaram altos desvios-padrões e médias próximas às medianas. Não houve nenhum dado perdido na amostra. 


\subsection{ANÁLISE ECONOMÉTRICA}

Antes de ajustar o modelo econométrico, foi calculado o VIF que permite analisar a relação entre as variáveis independentes. Na tabela 2, são evidenciados os resultados.

Tabela 2 - Teste VIF

\begin{tabular}{c|c|c}
\hline \multicolumn{3}{|c}{ Collinearity statistics } \\
\hline Variável & Tolerance & VIF \\
\hline ICC &, 0707 & 1,415 \\
\hline ICG &, 712 & 1,404 \\
\hline TAM &, 840 & 1,190 \\
\hline IDH &, 736 & 1,359 \\
\hline PIB &, 737 & 1,357 \\
\hline
\end{tabular}

Fonte: dados da pesquisa (2017).

De acordo com os resultados do teste VIF, podemos afirmar que as variáveis independentes não se relacionam fortemente uma com as outras, não havendo problemas de multicolinearidade. Na tabela 3, são apurados os resultados no que tange à existência ou não de relação entre os índices de transparência da administração pública com os índices de consistência e convergência contábil. que, quanto maior for o tamanho da população e quanto maior for o PIB do município, mais transparente na gestão pública serão os municípios pernambucanos.

Corroborando os achados desta pesquisa, resultados semelhantes foram encontrados em pesquisas na Espanha e em Portugal. Em estudo com os 100 maiores municípios espanhóis, Guillamón, Bastida e Benito (2011) analisaram o impacto dos fatores socioeconômicos e políticos no nível de transparência, um dos resultados apontou que o tamanho da população afeta, positivamente, o nível de transparência. Resultados semelhantes foram encontrados em pesquisa de Nogueira, Freitas e Ribeiro (2017), quando um dos achados da pesquisa apontou como determinante explicativo da transparência na gestão pública dos municípios portugueses o tamanho da população. Em outro estudo, com 306 municípios portugueses, realizado por Jorge, Sá e Lourenço (2012) mostram que o grau de transparência é genericamente baixo. Nomeadamente, evidenciam que a forma como a informação é disponibilizada não tende a promover a sua análise pelos cidadãos.

Tabela 3 - Regressão Linear Múltipla

\begin{tabular}{c|c|c|c|c|c|c|c|c}
\hline Variáveis & ICC & ICG & TAM & IDH & PIB & $\mathrm{R}^{2}$ & $\mathrm{R}^{2}$ Ajustadado & $\mathrm{F}$ \\
\hline ITM &, 158 &, 912 &, $019^{*}$ &, 610 &, $016^{*}$ &, 095 &, 070 &, 003 \\
\hline
\end{tabular}

Nota: *Significante a um nível de 5\%

Fonte: dados da pesquisa (2017).

Assim, diante dos resultados, não se aceita a hipótese $\mathrm{H}_{1}$ proposta nesta pesquisa, que foi verificar se existe relação positiva entre a transparência governamental com a consistência e convergência contábil nos municípios do estado de Pernambuco, pois foi verificado que, apesar de possuir uma relação positiva com o fato de os municípios serem consistentes e convergentes em relação à contabilidade, essa relação não tem significância estatística. Porém, as variáveis TAM e PIB foram estatisticamente significativas, o que nos leva a concluir

\subsection{ANÁLISE DE CORRESPONDÊNCIAS}

Para um aprofundamento no entendimento do objetivo proposto, foi aplicada, adicionalmente, técnica de Análise de Correspondência (Anacor). Para a utilização da Anacor, foram categorizadas tanto a variável referente ao índice de transparência Municipal/ITM como a variável correspondente às práticas de consistência e convergência contábil/PCC.

Para ambos os índices, os municípios fo- 
ram agrupados, segundo o que é esperado como resultado pelo próprio $\mathrm{TCE} / \mathrm{PE}$, que foi o elaborador dos índices.

Quadro 1 - Categorização do ITM/PE

\begin{tabular}{|l|l|}
\hline Nível de Transparência & Intervalo do ITM/PE \\
\hline Desejado & $>750<=1000$ \\
\hline Moderado & $>500<=750$ \\
\hline Insuficiente & $>250<=500$ \\
\hline Crítico & $>0 \quad<=250$ \\
\hline Inexistente & $=0$ \\
\hline
\end{tabular}

Fonte: TCE/PE (PERNAMBUCO, 2016).

Por meio do quadro 1, verifica-se que os níveis foram distribuídos de acordo com a pontuação obtida, referindo-se, por sua vez, aos desejado, moderado, insuficiente, crítico e inexistente.
Quadro 2 - Categorização do PCC/PE

\begin{tabular}{|l|l|}
\hline Nível de Transparência & Intervalo do ITM/PE \\
\hline Desejado & $=100 \%$ \\
\hline Aceitável & $>=90 \%$ e $<100 \%$ \\
\hline Moderado & $>=70 \%$ e $<90 \%$ \\
\hline Insuficiente & $>=50 \%$ e $<70 \%$ \\
\hline Crítico & $>50 \%$ \\
\hline
\end{tabular}

Fonte: TCE/PE (PERNAMBUCO, 2016).

De acordo com o quadro 2, verifica-se que os níveis foram distribuídos de acordo com a porcentagem obtida, referindo-se, por sua vez, aos desejado, aceitável, moderado, insuficiente e crítico.

Com o intuito de se verificar a associação entre os índices de transparência Municipal/ITM e o índice de consistência e convergência contábil/ICCC, procedeu-se à Análise de Correspondência (Anacor), levando-se em consideração as categorias preestabelecidas nos quadros 1 e 2 . O resultado pode ser visualizado na tabela 5 .

Tabela 5 - Tabela de correspondência

\begin{tabular}{|c|c|c|c|c|c|c|}
\hline \multirow{2}{*}{ ITM } & \multicolumn{6}{|c|}{$\mathrm{ICCC}$} \\
\hline & Desejado & Aceitável & Moderado & Insuficiente & Crítico & Margem Ativa \\
\hline Desejado & 0 & 0 & 0 & 1 & 0 & $1(1 \%)$ \\
\hline Moderado & 0 & 0 & 61 & 14 & 3 & $78(42 \%)$ \\
\hline Insuficiente & 0 & 0 & 58 & 9 & 2 & $69(38 \%)$ \\
\hline Crítico & 0 & 0 & 20 & 10 & 2 & $32(17 \%)$ \\
\hline Inexistente & 0 & 0 & 1 & 3 & 0 & $4(2 \%)$ \\
\hline Margem Ativa & 0 & 0 & $140(75 \%)$ & $41(22 \%)$ & $7(3 \%)$ & $184(100 \%)$ \\
\hline
\end{tabular}

Fonte: dados da pesquisa (2017).

Ao analisarmos o Índice de Consistência e Convergência Contábil/ICCC, chama a atenção que nenhum município alcançou as gradações "Desejável" ou "Aceitável”, o que, de fato, consiste em um alerta para os governos municipais do Estado de Pernambuco. Verifica-se que 140 municípios (75\%) encontram-se na gradação "Moderado" e outros 48 (25\%) municípios encontram-se "Insuficientes" ou "críticos".
Em relação ao Índice de Transparência Municipal/ITM, percebe-se que apenas 1 município alcança a gradação de "Desejado"; 78 municípios (42\%) são considerados "Moderados" e 104 municípios (55\%) são considerados "Insuficiente" ou "Crítico". Ademais, verifica-se, também, que, em 4 municípios (2\%), a transparência é considerada "Inexistente". Também esse índice consiste em um alerta, fica estampada a necessidade de os municípios pernambucanos em 
serem transparentes em sua gestão.

No que diz respeito à associação dos índices, a figura 1 evidencia o mapa perceptual da Anacor, que indica a associação entre o Índice de Transparência Municipal/ITM e o Índice de Consistência e Convergência Contábil/ICCC. $p=0,360$ ) que não permite estabelecer nenhuma dependência entre as variáveis, o que significa que as duas variáveis são independentes (não estão relacionadas). Assim, podemos afirmar que não se regista uma relação entre o índice de transparência municipal e o índice de con-

Figura 1 - Mapa perceptual do ITM x ICCC

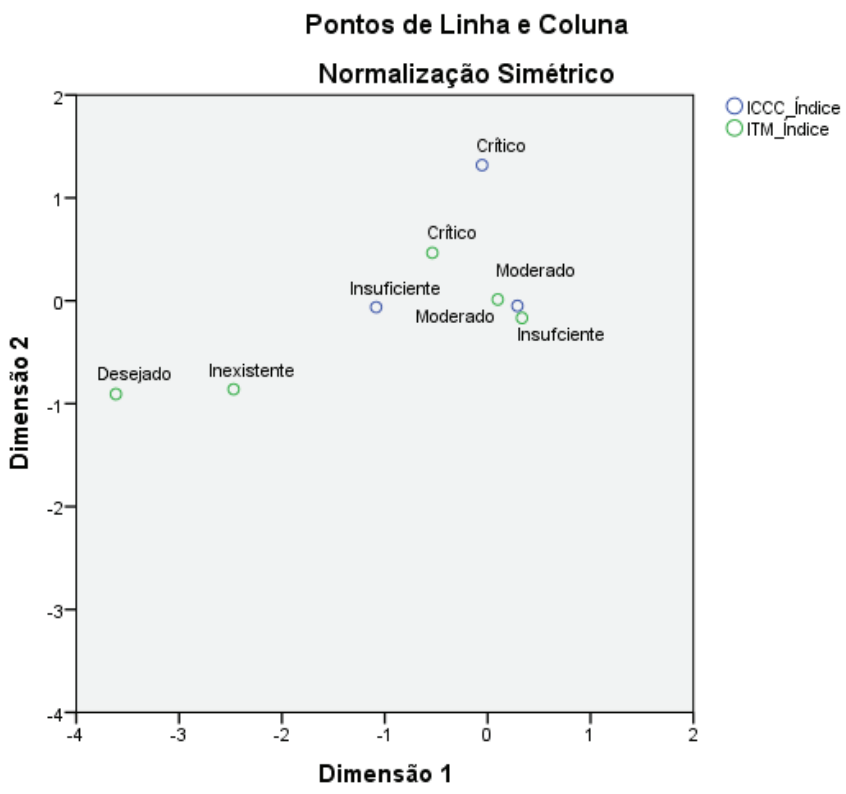

Fonte: dados da pesquisa (2017).

Na figura 1, verifica-se uma forte associação entre o "Moderado" do Índice de Transparência Municipal/ITM e o "Moderado" do Índice de Consistência e Convergência Contábi1/ICCC. Além dessa associação, as gradações "Crítico" de ambos os índices também estão associadas. Por fim, também cabe destacar que a gradação "Insuficiente" de ambos os índices também estão associadas.

Esses resultados indicam que os municípios necessitam melhorar as suas práticas de transparência e de Consistência e Convergência Contábil. Mais da metade dos municípios em relação à transparência são "Insuficientes", "Críticos" ou "Inexistentes". Em relação à Consistência e Convergência Contábil, 75\% dos municípios são "Moderados", e os restantes são "Insuficientes" ou "Críticos".

Essa análise revelou um valor de Qui-Quadrado não significativo $\left(X^{2}=17,411\right.$; sistência e convergência contábil.

\section{CONSIDERAÇÕES FINAIS}

Esta pesquisa teve como objetivo identificar a relevância da consistência e da convergência contábil no nível de transparência dos municípios do Estado de Pernambuco. A análise dos resultados foi composta de três partes: análise descritiva, econométrica e ANACOR.

Os principais resultados da análise descritiva apontaram que:

asmédiasdetransparênciadaadministração pública, consistência e convergência contábil foram, respectivamente de $42,2 \%$, $75,6 \%$ e $68,4 \%$;

alguns municípios não são transparentes em absolutamente nada no que tange à administração pública, recebendo nota zero no referido índice; 
as médias e medianas dos três índices são muito próximas.

A segunda parte da analise foi o teste da hipótese desta pesquisa, que testou a relação da transparência da gestão pública municipal com a consistência e a convergência contábil. Os resultados indicaram relação positiva, porém, não significativa para as variáveis dependentes. Diante desses resultados, rejeitamos a $\mathrm{H}_{1}$ proposta neste trabalho.

Por outro lado, as variáveis tamanho da população e PIB foram estatisticamente significativas, o que nos leva a concluir que, quanto maior for o tamanho da população e quanto maior for o PIB do município, mais transparente na gestão pública serão os municípios pernambucanos. De acordo com os resultados das pesquisas de Guillamón, Bastida e Benito (2011), Jorge, Sá e Lourenço (2012) e Nogueira, Freitas e Ribeiro (2017), esses resultados guardam semelhanças quando confrontados com os resultados de pesquisas nos municípios espanhóis e portugueses.

$\mathrm{Na}$ terceira e última parte da análise, foi realizada técnica de Análise de Correspondência (Anacor) com o objetivo de aprofundar o entendimento dos resultados até então obtidos. Verificou-se que grande quantidade (140 municípios - 75\%) encontram-se na gradação "Moderado", e outros 48 (25\%) municípios encontram-se "Insuficientes" ou "críticos" no que se refere ao Índice de Consistência e Convergência Contábil/ICCC. Em relação ao Índice de Transparência Municipal/ITM, a situação não é diferente, 104 municípios (55\%) são considerados "Insuficientes" ou "Críticos". Por fim, verificou-se forte associação entre o "Moderado" do Índice de Transparência Municipal/ITM e o "Moderado" do Índice de Consistência e Convergência Contábil/ICCC. Além dessa associação, as gradações "Crítico" de ambos os índices também estão associadas.

Fator de relevância que cabe destaque é que, diante de baixos resultados para os municípios em ambos os índices, o resultado "normal" para a hipótese proposta neste trabalho é não tenha sido aceita. Os resultados apontam que a transparência e a consistência e convergência contábil parecem que não são consideradas relevantes para os gestores municipais.

Em resposta ao título desta pesquisa, verificamos que existe relação positiva entre transparência da gestão pública municipal com a consistência e a convergência contábil; porém, sem significância estatística. Logo, não podemos afirmar que a transparência afeta a consistência ou a convergência contábil.

Para estudos futuros, sugere-se que novas variáveis sejam inseridas no modelo a fim de explicar as razões que levam os municípios a serem transparentes em sua gestão. Como limitação, podemos destacar o período desta pesquisa. Cabe ressaltar que os índices formulados pelo TCE/PE no ano de 2015 foram disponibilizados pela primeira vez e que, com o passar do tempo, será aprimorado (amadurecido).

\section{REFERÊNCIAS}

AMARAL, G. F.; LIMA, D. V. de. A contribuição da nova contabilidade pública sobre os efeitos dos ciclos políticos no Brasil. Revista Ambiente Contábil, v. 5, n. 2, p. 173, 2013.

BARROS, C. da C. et al. Transparência na gestão pública: um estudo do atendimento dos municípios do estado rio grande do norte a lei complementar $n^{\text {o }}$ 131/2009. Revista Ambiente Contábil, v. 9, n. 2, p. 200-221, 2017.

\section{BRASIL. Constituição da República Federa-} tiva do Brasil de 1988. Brasília, DF: Presidência da República, 1988. Disponível em: http:// www.planalto.gov.br/ccivil_03/constituicao/ constituicao.htm. Acesso em: 5 jan. 2020.

BRASIL. Lei Complementar $n^{0} 101$, de 4 de maio de 2000. Estabelece normas de finanças públicas voltadas para a responsabilidade na gestão fiscal e dá outras providências. Diário Oficial [da] República Federativa, Brasília, DF, 5 maio 2000.

CHRISTIAENS, Johan. Capital Assets in Gov- 
ernmental Accounting Reforms: Comparing Flemish Technical Issues with International Standards. European Accounting Review, v. 13, n. 4, p. 743-770, 2004.

CONSELHO FEDERAL DE CONTABILIDADE. Resolução n. ${ }^{\circ} \mathbf{1 . 1 0 3}$, de 28 de setembro de 2007: aprova a NBC T 16.3 - planejamento e seus instrumentos sob o enfoque contábil. Brasília: CFC, 2007.

CRUZ, C. F. et al. Transparência da gestão pública municipal: um estudo a partir dos portais eletrônicos dos maiores municípios brasileiros. Revista de Administração Pública, v. 46, p. 153-176, 2012.

DUTTA, Sunil; REICHELSTEIN, Stefan. Accrual accounting for performance evaluation. Review of Accounting Studies, v. 10, n. 4, p. 527-552, 2005.

ERNEST \& YOUNG. Toward transparency: a comparative study of governmental accounting in Europe. [S.l.]: Ernest \&Young, 2010.

FEIJÓ, Paulo Henrique; BUGARIM, Maria Clara Cavalcante. Portaria MF 184/2008: um marco para a implantação do Novo Modelo de Contabilidade Aplicada ao Setor Público. Revista Brasileira de Contabilidade, São Paulo, v. 173, p. 79-89, set./out. 2008.

GAMA, Janyluce Rezende; DUQUE, Claudio Gottschalg; ALMEIDA, José Elias Feres. Convergência brasileira aos padrões internacionais de contabilidade pública vis-à-vis as estratégias top-dow e bottom-up. Revista de Administração Pública, v. 48, n. 1, p. 183-206, 2014.

GUILLAMÓN, M.; BASTIDA, F.; BENITO, B. The determinants of local government's financial transparency. Local Government Studies, v. 37, n. 4, p. 391-406, 2011.

JORGE, S.; SÁ, P. M.; LOURENÇO, R. P. Transparência financeira nas entidades da ad- ministração local em Portugal: análise da informação disponibilizada nos sítios Web. Revista Portuguesa de Estudos Regionais, v. 31, 2012.

KREUTZ, Rafael Rudolfo; LOCK, Fernando Nascimento. Transparência em projetos públicos como ferramenta de controle das obras de mobilidade urbana. Revista Gestão em Análise, v. 9 , n. 3, p. 98-112, 2020.

MACÊDO, J. M. A. et al. Convergência contábil na área pública: uma análise das percepções dos auditores de TCES, contadores e gestores públicos. Revista de Contabilidade e Organizações, v. 4, n. 8, p. 69-91, 2010.

NOGUEIRA, Sônia P. da Silva; FREITAS, Ivone Amélia; RIBEIRO, Nuno A. Baptista. Determinantes da transparência na gestão pública dos municípios Portugueses. In: JORNADAS HISPANO-LUSAS DE GESTIÓN CIENTÍFICA, 27., 2017, Benidorm. Anais [...]. Benidorm, 2017.

NUNO, Ferreira da Cruz, et al. Measuring Local Government Transparency. Public Management Review, v. 18, n. 6, p. 866-893, 2016.

PAULO, Edilson; CARVALHO, Luiz Nelson Guedes; GIRÃO, Luiz Felipe de Araújo Pontes. Algumas questões sobre a normatização contábil baseada em princípios, regras e objetivos. Revista Evidenciação Contábil \& Finanças, v. 2, n. 2, p. 24-39, 2014.

PERNAMBUCO. Tribunal de Contas do Estado de Pernambuco. Índice de transparência da administração dos munícipios. 2016. Disponível em: http:/www.tce.pe.gov.br/indicedetransparencia2015/. Acesso em: 18 out. 2017.

PLATT NETO, O. A. et al. Publicidade e transparência das contas públicas: obrigatoriedade e abrangência desses princípios na administração pública brasileira. Contabilidade Vista \& Revista, v. 18, n. 1, 2007. 
SACRAMENTO, Ana R. Silva. Contribuições da Lei de Responsabilidade Fiscal para o avanço da accountability no Brasil. Cadernos Gestão Pública e Cidadania, v. 10, n. 47, 2005.

SILVA, L. M. Contabilidade governamental: um enfoque administrativo. 8. ed. São Paulo: Atlas, 2009.

SOARES, M.; SCARPIN, J. E. A convergência da contabilidade pública nacional às normas internacionais e os impactos na aplicação da DRE na administração direta. Revista Catarinense da Ciência Contábil, v. 9, n. 27, 2010.

SOUSA, Rossana G. et al. O regime de competência no setor público brasileiro: uma pesquisa empírica sobre a utilidade da informação contábil. Revista Contabilidade \& Finanças-USP, v. 24, n. 63, 2013.

TAVARES, Paulino Varela; ROMÃO, Ana Lúcia. Transparência, accountability e corrupção: uma percepção qualitativa da governança pública no Brasil e na África do Sul. Brazilian Journal of Development, v. 7, n. 3, p. 2359623633, 2021.

VEGA, R. O. M. et al. A nova contabilidade aplicada ao setor público: uma análise nos municípios do COREDE-FO. Revista de Gestão e Contabilidade da UFPI, Floriano, v. 2, n. 2, p. 33-50, jul./dez. 2015.

VICENTE, Ernesto Fernando Rodrigues; MORAIS, Leandro Morais; PLATT NETO, Orion Augusto. A reforma na contabilidade pública brasileira e o processo de convergência: implicações e perspectivas. RIC-Revista de Informação Contábil, v. 6, n. 2, p. 1-20, 2012.

VIGNOLI, Francisco Humberto (coord.). A Lei de Responsabilidade Fiscal comentada para municípios. São Paulo: FGV / EAESP, 2002.

WUSTEMANN, J.; WUSTEMANN, S. Why consistency of accounting standards matters: a contribution to the rules-versus-principles de- bate in financial reporting. Abacus, v. 46, n. 1, 2010.

ZEFF, Stephen A. Some obstacles to global financial reporting comparability and convergence at a high level of quality. British Accounting Review, v. 39, n. 4, p. 290-302, 2007. 